GASTRO-OESOPHAGEAL REFLUX

\title{
Effect of endoscopic augmentation of the lower oesophageal sphincter (Gatekeeper reflux repair system) on intraoesophageal dynamic characteristics of acid reflux
}

\author{
M Cicala, A Gabbrielli, S Emerenziani, M P L Guarino, M Ribolsi, R Caviglia, G Costamagna
}

Gut 2005;54:183-186. doi: 10.1136/gut.2004.040501

See end of article for authors' affiliations

\section{Correspondence to:}

DrM Cicala, Dipartimento di Malattie dell'Apparato Digerente, Università Campus Bio-Medico, Via Longoni, 83-00155 Rome (Italy);

m.cicala@unicampus.it

Received 11 February 2004 Accepted for publication 18 March 2004

\begin{abstract}
Background and aims: Improvements in symptoms following endoscopic procedures for gastrooesophageal reflux disease (GORD) are seldom supported by normalisation of acid exposure time at the distal oesophagus. However, the distribution of gastric acid within the proximal oesophagus is a main determinant of symptom generation in GORD patients. In this study, our aim was to assess the effect of endoscopic insertion of hydrogel expandable prostheses into the oesophageal submucosa on spatiotemporal characteristics of gastro-oesophageal reflux.

Methods: Oesophageal manometry and multichannel ambulatory 24 hour $\mathrm{pH}$ monitoring were carried out in nine patients before and six months after the endoscopic procedure. Dynamic characteristics of gastro-oesophageal reflux in patients were also compared with those in 13 asymptomatic controls.

Results: Acid exposure time (AET) at the distal oesophagus decreased from 11.7\% $195 \%$ confidence interval 6.1-21.8) at baseline to 7.7\% (3.7-11.6) at follow up (NS). Of the nine patients, distal AET normalised in three. AET at the middle (7.6\% (2.9-12.3)) and proximal $(2.4 \%(0.1-4.8))$ oesophagus decreased significantly in all patients $(2.4 \%(0.3-4.5), p<0.01 ; 1.2 \%(0.2-2.2), p<0.05$ respectively). Proximal extent of acid events significantly decreased in all patients at follow up $(37.3 \% \vee 9.5 \%)$, reaching values observed in asymptomatic controls. Median GORD health related quality of life scores significantly improved from 35.5 at baseline to 9.4 .

Conclusions: Despite the lack of a significant improvement in traditional $\mathrm{pH}$ variables, endoscopic implant of hydrogel prostheses above the lower oesophageal sphincter significantly decreases proximal spread of acid reflux into oesophageal body. This effect would explain the improvement in symptoms in patients six months after therapy.
\end{abstract}

augmentation of the LOS (Gatekeeper system), stationary oesophageal manometry and 24 hour multichannel $\mathrm{pH}$ monitoring were performed in GORD patients before and after the treatment. Dynamic characteristics of gastrooesophageal reflux in patients were also compared with those in asymptomatic controls.

\section{METHODS}

The study was carried out in nine GORD patients (four males, five females; mean age 48 years) meeting the inclusion criteria for the Gatekeeper procedure: (a) typical GORD symptoms, (b) pathological AET of the distal oesophagus ( 24 hour $\mathrm{pH}<4$ exceeding $4 \%$ of the total recording time), and (c) responsiveness to proton pump inhibitor (PPI) therapy. Exclusion criteria were: presence of Barrett oesophagus, hiatal hernia $>3 \mathrm{~cm}$, and erosive oesophagitis $>$ II grade (Savary-Miller). The Gatekeeper procedure consists of positioning 3-6 prostheses endoscopically at the level of the $\mathrm{Z}$ line in the submucosal layer of the oesophagus. Prostheses are made of polyacrylonitrile based hydrogel (non-immunogenic, non-migratory, and biocompatible) with tantalium for radio-opacity. All procedures were performed under deep sedation with propofol. The Gatekeeper system (Medtronic Inc.) consists of a specially designed $16 \mathrm{~mm}$ overtube assembly with a $2.4 \mathrm{~mm}$ prosthesis delivery system. The system allows the insertion of the endoscope inside the overtube and the procedure is under endoscopic vision. The

Abbreviations: GORD, gastro-oesophageal reflux disease; $A E T$, acid exposure time; LOS, lower oesophageal sphincter; PPI, proton pump inhibitor; HRQL, health related quality of life
To establish whether the intraoesophageal distribution and perception of acid reflux are affected by endoscopic
Previous studies have shown that spread of gastric acid win the proximal oesophagus, irrespective of AET in the distal oesophagus, is one of the main factor triggering symptoms in GORD patients with either erosive ${ }^{8}$ or nonerosive disease. ${ }^{9}$ 


\begin{tabular}{lll}
\begin{tabular}{l} 
Table 1 Gastro-oesophageal reflux disease- \\
health related quality of life (GORD-HRQL) \\
heartburn and regurgitation scores at baseline \\
and follow up \\
\hline \multicolumn{4}{l}{ Baseline } & 6 month follow \\
up score
\end{tabular} \\
Patient & score & 8 \\
IM & 37 & 0 \\
BM & 55 & 35 \\
EP & 26 & 2 \\
MC & 31 & 0 \\
NG & 12 & 0 \\
ED & 48 & 3 \\
AT & 32 & 10 \\
AM & 49 & $9.4(0-19)$ \\
IP & 30 & \\
Mean (95\% CI) & $35.5(25-46)$ \\
\hline
\end{tabular}

procedure has been described elsewhere. ${ }^{10}$ Of the nine patients, five presented with erosive disease (grade I in three, grade II in two patients) and the remaining four patients with non-erosive reflux disease. All patients completed the GORD-HRQL (health related quality of life) questionnaire and underwent stationary oesophageal manometry and a 24 hour ambulatory pH study before (range 6-12 days) and six months after Gatekeeper therapy. Manometric and $\mathrm{pH}-$ metric data pretreatment were compared with those of 13 asymptomatic hospital staff volunteers (five males, eight females; mean age 39 years) (healthy control group), all of whom were non-smokers. Oesophageal manometry was performed with a perfused device assembly that incorporated three distal openings for LOS pressure recording, radially oriented around the circumference, and side hole recording sites at 5, 10, and $15 \mathrm{~cm}$ above the distal opening. The catheter was passed transnasally and placed within the LOS high pressure zone. LOS resting pressure was measured at the end of the expiratory phase. Post deglutitive oesophageal motor function was assessed after a series of 10 wet (5-10 ml) swallows.

Ambulatory 24 hour oesophageal $\mathrm{pH}$ was monitored using a double probe, each with two antimony sensors, with a separate skin reference (Zinetics Medical Inc., Salt Lake City, Utah, USA). Data were stored on a single portable digital recorder (Digitrapper pH200; Medtronic).

Before each study, the $\mathrm{pH}$ probes were calibrated in buffer solutions of $\mathrm{pH} 7$ and $\mathrm{pH} \mathrm{l}$. The four $\mathrm{pH}$ sensors were placed, according to the manometric findings, at the gastric level, $5 \mathrm{~cm}$ above the LOS, and 10 and $3 \mathrm{~cm}$ below the upper oesophageal sphincter. Patients and controls completed a diary card on which the times of meals, body position, and time and type of symptoms were reported.

Patients on antisecretory and/or prokinetic drugs stopped all treatment at least three weeks before the first $\mathrm{pH}$
Table 2 Mean basal lower oesophageal sphincter (LOS) pressure and LOS length at baseline and follow up

\begin{tabular}{|c|c|c|c|c|}
\hline \multirow[b]{2}{*}{ Patient } & \multicolumn{2}{|c|}{$\begin{array}{l}\text { Mean LOS basal } \\
\text { pressure }\end{array}$} & \multicolumn{2}{|c|}{ LOS length $(\mathrm{cm})$} \\
\hline & Baseline & $\begin{array}{l}6 \text { month } \\
\text { follow up }\end{array}$ & Baseline & $\begin{array}{l}6 \text { month } \\
\text { follow up }\end{array}$ \\
\hline IM & 9.2 & 14.6 & 1.5 & 2.0 \\
\hline BM & 21.0 & 17.9 & 2.5 & 3.0 \\
\hline EP & 12.3 & 9.3 & 2.0 & 2.5 \\
\hline$M C$ & 11.4 & 9.2 & 2.0 & 2.5 \\
\hline NG & 7.8 & 6.7 & 3.0 & 2.5 \\
\hline ED & 9.2 & 19.7 & 1.5 & 1.5 \\
\hline AT & 11.2 & 15.1 & 2.5 & 3.0 \\
\hline$A M$ & 13.2 & 29.8 & 3.0 & 3.5 \\
\hline $\mathbb{I P}$ & 14.1 & 15.2 & 4.0 & 3.8 \\
\hline Mean & 12.1 & 15.3 & 2.4 & 2.7 \\
\hline (95\%Cl) & $(9-15)$ & $(10-20)^{*}$ & $(1.8-3)$ & $(2.1-3.2)^{*}$ \\
\hline
\end{tabular}

monitoring. According to the procedure protocol, patients were treated with esomeprazole ( $40 \mathrm{mg}$ daily) for two weeks after the procedure and then stopped PPI therapy up to the end of the study. None of the patients or controls in the study population had a history of gastrointestinal surgery, with the exception of appendicectomy. Written informed consent was obtained from all individuals and the study protocol was approved by the ethics committee of Campus Bio Medico University of Rome.

\section{Analysis of data}

A reflux episode was defined as a pH drop below 4 units at the distal oesophageal sensor, lasting $\geqslant 4$ seconds. If the $\mathrm{pH}$ dropped to below 4 in the middle or in both the middle and proximal oesophagus and occurred simultaneously with a similar $\mathrm{pH}$ drop in the distal oesophagus, the reflux episode was defined as proximal (propagated reflux). ${ }^{9}$ To assess proximal propagation of each reflux episode, analysis of the $\mathrm{pH}$ tracing was performed by the same operator. Duration of each reflux episode was assessed at the three oesophageal sensors.

AET was defined as pathological, at the level of the distal oesophagus, if the percentage of time during which $\mathrm{pH}<4$ exceeded the upper limits of normal values (5\%) for the total recording time. ${ }^{11}$ Reflux episodes were classified as symptom related if they occurred $\leqslant 2$ minutes before the onset of symptom. ${ }^{12}$ Heartburn and/or acid regurgitation were considered in the analysis of symptoms. Symptom index and symptom association probability index were calculated at each oesophageal level (Software Medtronic, Minneapolis, Minnesota, USA) according to the formula described previously. ${ }^{13} 14$

Table 3 Dynamic characteristics of acid reflux in healthy controls

\begin{tabular}{|c|c|c|c|c|}
\hline & \multicolumn{2}{|c|}{ Reflux episodes (n) } & \multicolumn{2}{|c|}{ Duration (minutes)* } \\
\hline \multirow[t]{2}{*}{ Distal oesophagus } & \multicolumn{2}{|l|}{439} & \multicolumn{2}{|l|}{$0.7(0.4-1)$} \\
\hline & Upright & Supine & Upright & Supine \\
\hline \multirow{3}{*}{ Middle oesophagus } & 329 & 110 & $1.1(0.1-2.1)$ & $0.5(0.4-0.7)$ \\
\hline & 33 & & $1.1(0.4-1.9)$ & \\
\hline & 28 & 5 & $0.9(0.3-1.5)$ & $2(0-5)$ \\
\hline \multirow[t]{2}{*}{ Proximal oesophagus } & 5 & & $0.6(0.2-0.9)$ & \\
\hline & 4 & 1 & $0.5(0-1.1)$ & $0.5(0.1 .8)$ \\
\hline
\end{tabular}




\begin{tabular}{|c|c|c|c|c|c|c|c|c|}
\hline & \multicolumn{4}{|c|}{ Reflux episodes (n) } & \multicolumn{4}{|c|}{ Duration (minutes) $\dagger$} \\
\hline & \multicolumn{2}{|c|}{ Pretreatment } & \multicolumn{2}{|c|}{ Post treatment } & \multicolumn{2}{|l|}{ Pretreatment } & \multicolumn{2}{|l|}{ Post treatment } \\
\hline \multirow[t]{2}{*}{ Distal oesophagus } & 469 & & 564 & & $1.6(1.3-1.8)$ & & $1.2(0.9-1.5)$ & \\
\hline & Upright & Supine & Upright & Supine & Upright & Supine & Upright & Supine \\
\hline \multirow[t]{2}{*}{ Middle oesophagus } & $\begin{array}{l}312 \\
175\end{array}$ & 157 & $\begin{array}{r}342 \\
54\end{array}$ & 222 & $\begin{array}{l}1.5(1.2-1.8) \\
2.3(2.0-2.8)\end{array}$ & $1.8(1.3-2.2)$ & $\begin{array}{l}1.1(0.8-1.6) \\
1.6(0.8-2.3)^{\star \star *}\end{array}$ & $1.1(0.8-1.5)$ \\
\hline & 106 & 69 & 49 & 5 & $2.3(1.8-2.9)$ & $2.5(1.9-3.1)$ & $1.6(0.7-2.4)$ & $1.2(0.4-2.4)$ \\
\hline \multirow[t]{2}{*}{ Proximal oesophagus } & 76 & & 32 & & $1.9(1.3-2.5)$ & & $0.9(0.6-1.1)^{\star * *}$ & \\
\hline & 41 & 35 & 29 & 3 & $1.4(0.8-1.9)$ & $2.5(1.4-3.6)$ & $0.8(0.5-1.1)$ & $0.7(0.4-1.9)$ \\
\hline
\end{tabular}
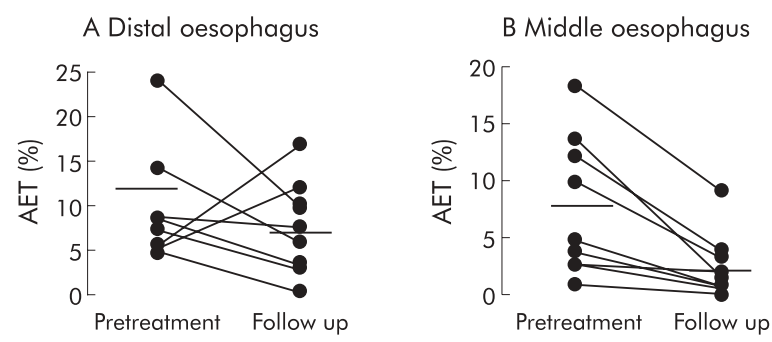

\section{Statistical analysis}

Data are expressed as mean and 95\% confidence intervals (95\% CI). The Wilcoxon test was used to compare intrasubject differences in reflux events.

\section{RESULTS}

\section{Symptoms}

The GORD-HRQL (heartburn and regurgitation) score, off PPI, significantly improved from a value of 35.5 (95\% CI 25$46)$ at baseline to 9.4 (95\% CI $0-19)$ at six months ( $p<0.01)$ (table 1). All patients except one showed significant improvement in the symptom score after six months of follow up.

\section{Manometric data}

No significant differences were found for resting and residual LOS pressure, LOS length (table 2), or motor patterns of the oesophageal body between baseline and the six month follow up. Simultaneous waves and/or abnormal amplitude waves ( $<30 \mathrm{~mm} \mathrm{Hg}$ or $>180 \mathrm{~mm} \mathrm{Hg}$ ) were not observed pre or post therapy in patients or controls.

\section{pHmetric data}

Spatiotemporal characteristics of the reflux events in healthy controls and in patients before and at six months after treatment are shown in tables 3 and 4 .

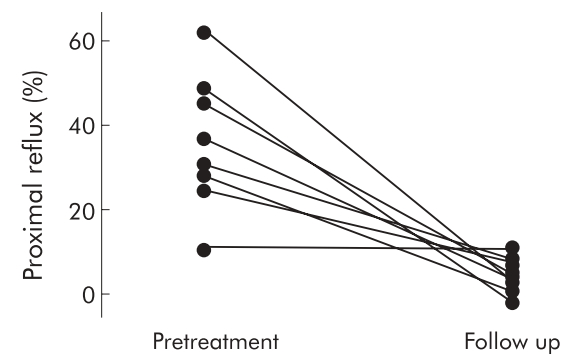

Figure 2 Proximal reflux before treatment and after six months of follow up.

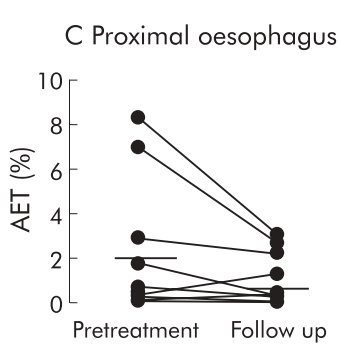

Figure 1 Acid exposure time (AET) at different oesophageal levels, before treatment and after six months of follow up.
In healthy controls, mean AET $(\% \mathrm{pH}<4)$ was $1.7 \%(95 \%$ CI $0.8-2.6)$ at the distal oesophagus, $0.4 \%(0.1-0.8)$ at the middle oesophagus, and $0.4 \%(0.02-0.8)$ at the proximal oesophagus.

In patients, AET at the distal oesophagus decreased, although not significantly, from $11.7 \%$ (95\% CI 6.1-21.8) at baseline to $7.7 \%(3.7-11.6)$ after six months of follow up (NS). Of the nine patients, distal AET normalised in three. AET at the middle $(7.6 \%(2.9-12.3))$ and proximal $(2.4 \%$ $(0.1-4.8))$ oesophagus decreased significantly six months after endoluminal therapy in all patients $(2.4 \%(0.3-4.5)$, $\mathrm{p}<0.01 ; 1.2 \%(0.2-2.2), \mathrm{p}<0.05$, respectively). Individual data are shown in fig 1 .

Proximal extent (number of proximal refluxes/number of distal refluxes) of acid reflux in healthy controls was $9.8 \%$ (95\% CI 7.2-12.9). Proximal extent of acid reflux in the patient group was $37.3 \%(32-42)$ at baseline and 9.5\% (7.3$12.3)$ at follow up $(\mathrm{p}<0.01)$. After therapy, proximal extent in all patients was within the range observed in healthy subjects. Individual data are shown in fig 2.

\section{DISCUSSION}

The aim of this study was to evaluate the effect of insertion of expandable prostheses into the submucosa of the distal oesophagus on spatiotemporal characteristics of gastrooesophageal reflux. For this purpose, prolonged multichannel $\mathrm{pH}$ monitoring was performed. Indeed, although the main determinants of GORD symptoms still remain to be fully elucidated, studies using intraluminal impedance monitoring in combination with $\mathrm{pH}$ and bile monitoring have confirmed the hypothesis that of the gastric contents, acid reflux plays a major role in eliciting symptoms and, at the same time, is related to disease complications. ${ }^{15-18}$ The results of the present study concerning symptoms and $\mathrm{pH}$ profile of GORD patients showed, in agreement with the findings of an ongoing multicentre study, ${ }^{19}$ that the satisfactory improvement in symptoms following therapy was not associated with normalisation of acid exposure of the distal oesophagus in the majority of patients. In our series, after six months of follow up, despite a positive subjective response to the treatment in almost all patients, AET at the distal oesophagus normalised 
in only three of our nine patients. Furthermore, lack of significant improvement in manometric findings (that is, LOS tone and post deglutitive motor patterns) did not support the subjective improvement, reported in terms of GORD-HRQL score and the need for antisecretory drugs.

It has recently been shown that proximal oesophageal extent of gastric acid is a common finding in GORD and a main determinant of reflux perception, irrespective of AET of the distal oesophageal mucosa. ${ }^{9}$ Our results on intraoesophageal patterns of acid reflux demonstrated a significant decrease, post therapy, of ascending (proximal) reflux at the middle and proximal oesophageal levels. The decreased acid exposure of the proximal oesophageal mucosa occurred in all patients, and at follow up reached values observed in asymptomatic controls, in terms of AET as well as percentage of proximal extent. Others have previously reported 24 hour $\mathrm{pH}$ data for the proximal oesophagus in asymptomatic subjects, ${ }^{20}$ and our findings are in agreement with these, confirming that in the patient group, AET of the proximal, but not of the distal, oesophagus normalised six months after the procedure. Data for $\mathrm{pH}$ variables according to body position in patients confirm previous findings that most of the reflux episodes occur and reach the proximal oesophagus while in an upright position but mean duration is longer in the supine position. ${ }^{21}$ The longer duration of reflux events in the supine position, reported to be a pathophysiological marker of GORD patients, was no longer present at follow up.

The correlation between gastro-oesophageal reflux and GORD symptoms remains to be fully elucidated but increasing evidence supports the role of gastric acid, and possibly of its intraoesophageal extent, on histological and ultrastructural changes in the oesophageal mucosa (basal cell hyperplasia, papillary elongation, and intercellular space dilation) which may lead to increased chemoreceptor activation, even in the absence of erosive oesophagitis. ${ }^{22-24}$ It is tempting to hypothesise that the reduced contact time of gastric acid on the entire oesophageal mucosa, due to enhanced reflux resistance at the level of the oesophagogastric junction, may play a role in symptom improvement, irrespective of acid exposure at the distal oesophagus alone. Furthermore, it has recently been shown that GORD patients, particularly those with a hiatus hernia, are characterised by a wider opening of the relaxed oesophagogastric junction and it has been speculated that endoscopic therapies may be beneficial by decreasing oesophagogastric junction compliance and, most probably, the volume of the refluxate..$^{25}$ Our study could not evaluate this effect as $\mathrm{pH}$ measurement gives no indication of the volume of the refluxate.

In the present study, the effect of the Gatekeeper procedure on the dynamic pattern of acid reflux was assessed after a short follow up period in a small group of patients. Long term observations are now needed to establish whether and for how long these changes persist, as well as their long term relationship with the symptoms and complications of the disease. Pathophysiological studies carried out on larger series undergoing endoluminal therapies may support our findings and would offer objective parameters for the outcome of these new therapeutic approaches for GORD.

In conclusion, despite the lack of a significant improvement in traditional $\mathrm{pH}$ variables, endoscopic insertion of hydrogel prostheses above the LOS significantly decreased proximal spread of acid reflux within the oesophageal body. This effect would explain the significant improvement in symptoms in GORD patients, six months after this therapy.
Authors' affiliations

M Cicala, A Gabbrielli, S Emerenziani, M P L Guarino, M Ribolsi,

R Caviglia, Department of Digestive Disease, University Campus Bio Medico, Rome, Italy

G Costamagna, Endoscopy Unit, Catholic University, Rome, Italy

Conflict of interest: None declared.

\section{REFERENCES}

1 Triadafilopouls G, DiBiase JK, Nonstrant TT. Radiofrequency energy delivery to gastroesophageal junction for treatment of gastroesophageal reflux disease. Gastrointest Endosc 2001:53:407-15.

2 Johnson DA, Ganz R, Aisenberg J, et al. Endoscopic implantation of enteryx for treatment of GERD: 12-month results of a prospective, multicenter trial. Am J Gastroenterol 2003;98:1921-30.

3 Filipi CJ, Lehman GA, Rothstein RI, et al. Transoral, flexible endoscopic suturing for treatment of GERD: a multicenter trial. Gastrointest Endosc 2001;53:416-22

4 Triadafilopouls G, DiBiase JK, Nonstrant TT, et al. The Stretta procedure for the treatment of GERD: 6 and 12 month follow-up of the U.S. open label trial. Gastrointest Endosc 2002;55:149-56.

5 Hogan WJ, Shaker R. A critical review of endoscopic therapy for gastroesophageal reflux disease. Am J Med 2003;115:201S-10.

6 Pleskow D, Rothstein R, Lo S, et al. Endoscopic full-thickness plication for the treatment of GERD: A multicenter trial. Gastrointest Endosc 2004;59:163-71.

7 Fockens PJ, Bruno M, Costamagna G, et al. Endoscopic augmentation of the lower esophageal sphincter for the treatment of GERD: multicenter study of the gatekeeper reflux repair system. Gastrointest Endosc 2003;57:AB97.

8 Weusten BL, Akkermans LM, van Berge-Henegouwen GP, et al. Symptom perception in gastroesophageal reflux disease is dependent on spatiotemporal reflux characteristics. Gastroenterology 1995; 108:1739-44.

9 Cicala M, Emerenziani S, Caviglia R, et al. Intra-oesophageal distribution and perception of acid reflux in patients with non-erosive gastro-oesophageal reflux disease. Aliment Pharmacol Ther 2003;18:605-13.

10 Fockens P. Gatekeeper TM reflux repair system: technique, preclinical and clinical experience. Gastrointest Endosc Clin N Am 2003;13:179-89.

11 Smout AJ, Breedijk M, van der Zouw C, et al. Physiological gastroesophageal reflux and esophageal motor activity studied with a new system for 24-hour recording and automated analysis. Dig Dis Sci 1989;34:372-8.

12 Lam HG, Breumelhof R, Roelofs JM, et al. What is the optimal time window in symptom analysis of 24-hour esophageal pressure and $\mathrm{pH}$ data? Dig Dis Sci 1994;39:402-9.

13 Wiener GJ, Richter JE, Copper JB, et al. The symptom index: a clinically important parameter of ambulatory 24-hour esophageal $\mathrm{pH}$ monitoring. Am J Gastroenterol 1988:83:358-61.

14 Weusten BL, Roelofs JM, Akkermans LM, et al. The symptom-association probability: an improved method for symptom analysis of 24-hour esophageal pH data. Gastroenterology 1994;107:1741-5.

15 Vela MF, Camacho-Lobato L, Srinivasan R, et al. Simultaneous intraesophageal impedance and $\mathrm{pH}$ measurement of acid and non-acid gastroesophageal reflux: effect of omeprazole. Gastroenterology $2001 ; 120: 1599-606$

16 Koek GH, Tack J, Sifrim D, et al. The role of acid in duodenal gastroesophageal reflux in symptomatic GERD. Am J Gastroenterol 2001;96:2033-40

17 Sifrim D, Holloway R, Silny J, et al. Acid, non-acid, and gas reflux in patients with gastroesophageal reflux during ambulatory 24 -hour $\mathrm{pH}$-impedence recordings. Gastroenterology 2001;120:1588-98.

18 Taha AS, Balsitis M, Angerson WJ, et al. Oesophagitis and bile reflux gastritis: clinical and histological assessments. Dig Liv Dis 2003 Oct; $35: 701-5$.

19 Fockens $P$, Boeckxstaens $G$, Costamagna $G$, et al. Gatekeeper reflux repair system: multicenter European study. Gut 2003:52(suppl 6):A47.

20 Dobhan R, Castell DO. Normal and abnormal proximal esophageal acid exposure: results of ambulatory dual-probe $\mathrm{pH}$ monitoring. Am J Gastroenterol 1993;88:25-9.

21 Weusten BL, Akkermans LM, Van Berge-Henegouwen GP, et al. Dynamic characteristics of gastro-oesophageal reflux in ambulatory patients with gastro-oesophageal reflux disease and normal control subjects. Scand J Gastroenterol 1995;30:731-7.

22 Tobey NA, Carson JL, Alkiek RA, et al. Dilated intercellular spaces: a morphological feature of acid-reflux damaged human esophageal epithelium. Gastroenterology 1996;111:1200-5.

23 Calabrese C, Fabbri A, Bortolotti M, et al. Dilated intercellular spaces as a marker of oesophageal damage: comparative results in gastro-oesophageal reflux disease with or without bile reflux. Aliment Pharmacol Ther 2003; 18:525-32.

24 Tobey NA, Hosseini SS, Argote CM, et al. Dilated intercellular spaces and shunt permeability in nonerosive acid-damaged esophageal epithelium. Am J Gastroenterol 2004;99:13-22.

25 Pandolfino JE, Shi G, Trueworthy B, et al. Esophagogastric junction opening during relaxation distinguishes nonhernia reflux patients, hernia patients, and normal subjects. Gastroenterology 2003;125:1018-24. 